\title{
RESEARCH METHODOLOGIES FOR ASSESSING THE ERGONOMICS OF PACKAGING PRODUCTS - A REVIEW
}

\author{
Gordana Bošnjaković (D), Gojko Vladić (D) \\ University of Novi Sad, Faculty of Technical Sciences, \\ Department of graphic engineering and design, Novi Sad, Serbia
}

\begin{abstract}
In today's increasingly competitive market environment, new packaging must meet more requirements than before to meet customer expectations. The packaging must meet not only functional and aesthetic requirements but also ergonomic requirements to ensure satisfying user experience. An important issue in ergonomic design is the identification of factors that lead to user comfort and discomfort. The packaging is a product that undergoes manual manipulation and given the various forms of packaging and it's opening and closing systems, they require using different grip types and movements. Using packaging that is not well designed can cause intense physical exertion and frustration for users. The subject of this paper is a review of methodologies for assessing the ergonomics of packaging products. Methodologies for evaluating the ergonomic characteristics of packaging provide a proposal for structuring the investigation. Also, it gives a proposal for the proper prioritization of a packaging problem that should be identified as the most dangerous risks for physical injuries or for causing stressful situations to users. First, it is necessary to gain a clear insight into how the users handle the packaging in order to create knowledge and a clear idea of what is useful or harmful in the existing packaging design and to find the potential for its improvement. There are various methods for studying, analyzing and evaluating user experience while using a packaging. Combining such methods with knowledge of the anatomical structure of the body and how it reacts to the load enables the creation of efficient and ergonomically designed packaging. This paper will present methodologies and guidelines for assessing and improving the ergonomic qualities of packaging. The aim of this paper is to define the key factors and most relevant methodologies for conducting successful ergonomic research.
\end{abstract}

Keywords: ergonomics, packaging, methods

\section{INTRODUCTION}

\subsection{Ergonomics}

Ergonomics is a scientific discipline that deals with understanding the interactions between people and other elements of the system applying theory, principles, data and design methods, in order to optimize human well-being and overall system performance (Dul, 2008; Chebykin, Bedny and Karwowski, 2008; Bridger, 2003; Salvendy, 2012; Stanton et al, 2014). Knowledge of ergonomic design is focused on the relationship between objects and environments and human factors (Kaljun and Dolšak, 2012). In the human-workplace interaction, the workplace must be adapted to the worker so that he/she can safely perform his/her task. Therefore, the ergonomic design of the workroom, tools, furniture and products (Figure 1) must be based on the anthropometry and biomechanics of the human body (Oyewole et al, 2010; Hashim and Dawal, 2012).

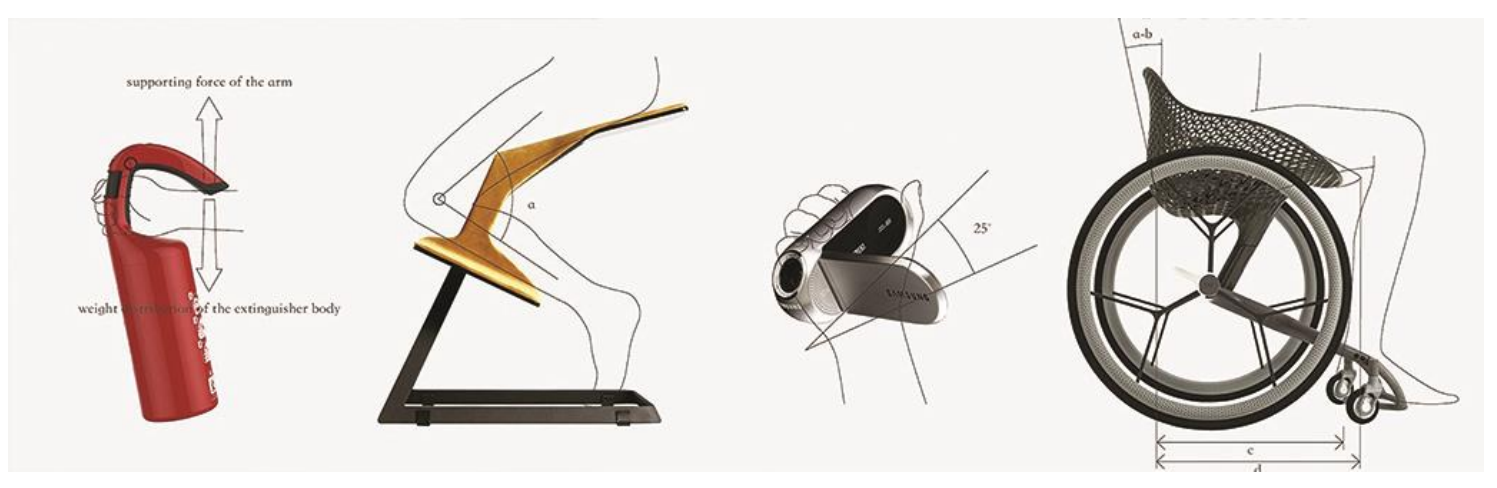

Figure 1: Examples of ergonomically designed products (Points, 2019) 
Anthropometry (Greekanthropos $=$ man, methros $=$ measure) is a bioanthropological method that deals with measuring the physical dimensions of the human body, processing and analysis of the obtained measures. It quantitatively determines the morphological characteristics of the body and provides objective information about the growth state of the examined person (Rogulj et al, 2012; Sudarov and Fratić, 2010). Biomechanics is a science focused on forces and their effects applied to biological systems (Freivalds, 2011). The general goal in the biomechanics of handles and tools is to optimize the relationship between the handle and the user in the sense of ensuring the use of the handle while avoiding the possibility of physiological and musculoskeletal problems (Kumar, 1999). The design, selection and installation of tools, such as those used in production and construction, are often done without considering the specific intensity of the forces required to be applied when using the tool, or any product that is a subject to manual manipulation. It is often done without considering the user's abilities, whether he/she can support the tool and produce necessary forces. Although sometimes these forces can be measured directly while product is in use, this is often not practical and it is preferable to predict the strengths, capabilities, limits, and tolerances of users before using the product (Armstrong et al, 2010).

\subsection{Packaging in interaction with the consumer}

The packaging is an unformed or formed material in which a product is packed, in order to protect it and transport it safely or to make an easier purchase or use of the product (Novaković, 2013). The packaging has reached high quality in terms of the functions it needs to fulfil: protection from external influences, barrier properties, aesthetic functions, providing information and presenting the product that is packed in, etc. However, there is another requirement that packaging should fulfil and that is the ease of opening and use of the product packed in it (Figure 2). Sometimes this is a challenge not only for consumers of the older generation and those who suffer from rheumatoid arthritis and osteoarthritis arthritis, but the entire population sometimes faces a similar problem. To design and produce a packaging that will solve these problems, it is necessary to define the most important factors affecting consumers when opening and using packaging. When the factors are defined, it is necessary to create a packaging design that will be in accordance with these factors. This paper will cover all the important factors that need to be considered during the development of an ergonomic packaging:

- Physical qualifications and consumer capabilities for easy product handling,

- Critical aspects when using the product,

- Methods for researching consumer opportunities and critical aspects when using products and for evaluating the ergonomic characteristics.
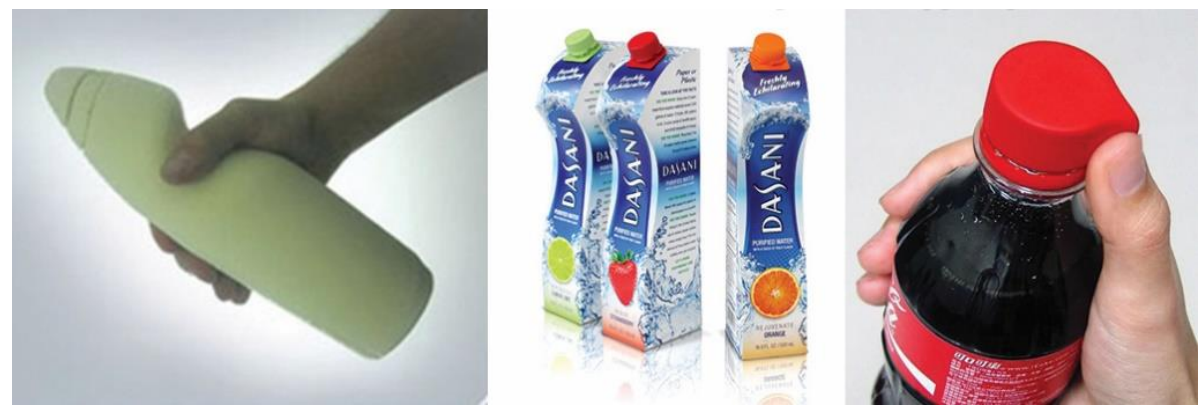

Figure 2: Examples of ergonomically designed packaging

The subject of this paper is a review of methodologies for assessing the ergonomics of packaging products, ie. the methodologies that can be implemented when developing, analyzing and evaluating work tasks and specific products. The methodologies explain how to assess ergonomic characteristics concerning one or more physical load factors. The described methodologies for evaluating the ergonomic characteristics of products provide a proposal for structuring the analysis the investigation and a proposal for approaching prioritization by identifying the greatest risks for physical injuries to users/causing stressful situations. It is first necessary to gain a clear insight into how the consumer uses the product to create knowledge and a clear idea of what is useful or harmful in the existing product design solution and to find the potential for its improvement. There are various methods for studying, analyzing and evaluating users while using a product. Combining such methods with knowledge of the anthropometrics and biomechanics enables the design of efficient and ergonomically designed packaging. 


\section{PHYSICAL QUALIFICATIONS AND CAPABILITIES OF CONSUMERS FOR EASY PRODUCT HANDLING}

Different techniques and methods have been developed and used to measure different aspects of a user's physical qualifications and abilities. Most of them are based on the measurement of human strength using various mechanical devices, which has limitations in their applicability to actual daily activities. Extensive research has been done that includes a series of publications containing ergonomic data for use in the design of consumer products. There are publications on children, adults, and older adults (Norris and Wilson, 1995; Peebles and Norris, 1998; Smith et al, 2000) with human factor data on these three groups and have been used for packaging design, but "gaps" in the data available for direct use in packaging design were discovered. These difficulties have triggered new research and collected new data on user strengths such as finger pressure strength, pull strength, hand grip strength, wrist-twisting strength, and pressure and pull strength (Peebles and Norris, 2003). Research has also been conducted on the difficulties that people with disabilities or people with severe physical difficulties have in everyday life and with this, a number of problematic products have been identified, one of which is packaging (Nordenskiöld, 1996; Rosengren and Brodin, 2013). In addition to identifying the products that people with disabilities had the most problems with, research also identified strategies that people with disabilities had to use while dealing with products. These strategies mainly involved special ways of reaching, grasping and lifting. Often products that require coordinated movement with two hands, e.g. unscrewing the jar of jam was complicated and difficult. Researchers have also tried to gain insight into the types of grips that users typically use (Rowson and Yoxall, 2011). Data on the physical abilities of persons with disabilities for several hand functions can be found in the report "Specific Anthropometric and Strength Data for People with Dexterity Disability" (Consumer and Competition Policy Directorate, 2002). There are significant differences between the abilities of people with disabilities and people without disabilities. In all tests, the strength of healthy people was between two and three times higher that of people with disabilities, which is a significant challenge for packaging designers and manufacturers if they want to produce products that people with disabilities will be able to use with the same degree of ease and convenience that is expected from healthy people. For example, the unscrewing forces of the jar lid should be limited to a torque of only $0.25 \mathrm{Nm}$ so that people with hand limitations can open the product. Also opening a package that involves pulling on small tabs will have to be limited to pulling that requires a force level of approximately $5 \mathrm{~N}$, to match the capabilities of people with hand problems. However, many of the tests used to measure strength do not represent the exact operations used to open the packaging, and human strength is highly dependent on the action being performed. Also, as age increases, strength begins to decline rapidly and even seemingly small changes in material or geometry can have a major impact on the force a person can apply. When the ease of use of a product is viewed from the user's point of view, several factors can be defined that can affect the ease of use of the product: strength in hands, skin sensitivity, dexterity, lefthandedness/right-handedness, coordination, pain, cognition, sight, attention, memory and problem solving, personality. When using the product, consumers are required to use different movements and apply force. Some of the movements that are necessary to avoid are "key grip", "power grip", twisting or rotation of the wrist (Heinö et al, 2008). The position of the whole arm and spine must be considered, especially when it comes to frequent lifting of loads so that muscle and spine injuries can be avoided (Moore et al, 2011). An illustration of the neutral and awkward position of the wrist is given in Figure 3.

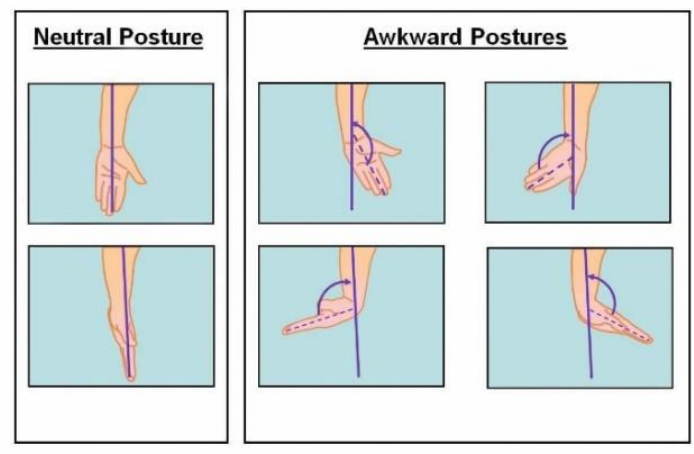

Figure 3: Neutral and awkward wrist position (Moore et al, 2011) 
To get information about human forces, force measuring device, the so-called. dynamometers are often used in research. They come with different extensions suitable for different tasks and equipment and they are relatively inexpensive and easy to use (Figure 4).

a)

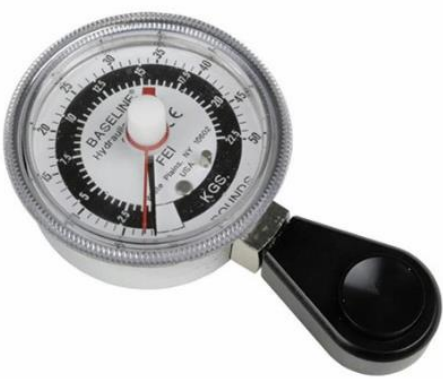

b)

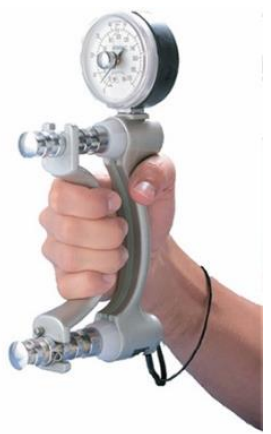

Figure 4: Example of dynamometers for measuring force

a) for thumb and fingers b) for whole hand (Avramović, 2018; Baseline, 2018)

Advanced testing techniques that are used are electromyography (EMG), measuring contact pressure using flexible force sensors, postural technique, etc. (Figures 5 and 6).

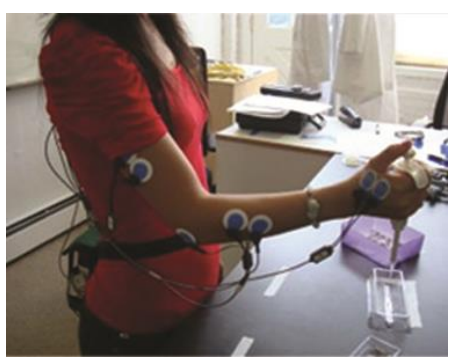

Figure 5: Electromyography equipment (US-Ergo, 2019)

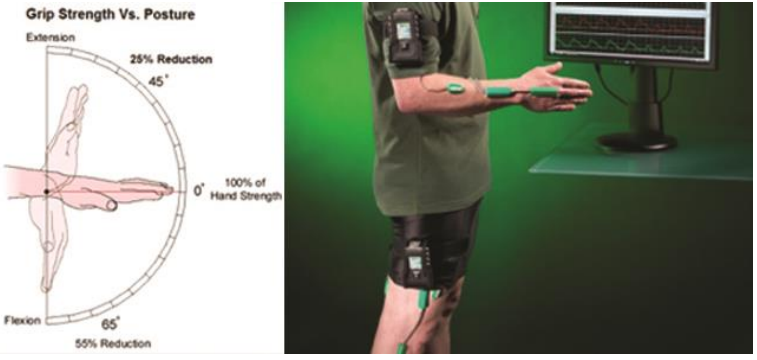

Figure 6: Postural technique (US-Ergo, 2019)

\section{CRITICAL ASPECTS WHILE USING THE PACKAGING}

There are different types of packaging opening mechanisms. The most critical factors influencing the ease of opening a packaging are visibility and clarity of the opening mechanism, the position of the opening mechanism relative to the holding position, tightness/brittleness and fragility of the opening mechanism, the strength required to open packaging, the need to use both hands when opening, the strength and slipperiness of the packaging material, required grip of the packaging, breakage of the packaging during the opening and the degree of retention of the product in the packaging after opening (Kroemer Elbert, Kroemer and Kroemer Hoffman, 2018).

\section{METHODS FOR EVALUATION OF THE ERGONOMIC CHARACTERISTICS OF PACKAGING PRODUCTS}

Methods for assessing critical aspects of using products can be divided into subjective methods, objective methods, combined methods and usability methods.

\subsection{Subjective methods}

When a product should be evaluated based on the comfort it provides to the user, subjective methods and measurements are most often used. Most of them are focused on the discomfort that the user feels when using the product. Although the validity and usefulness of subjective measurements are often questioned, Johnson (1999) emphasizes the use of subjective assessments of comfort, productivity, and ease of use of a product. Subjective comfort and discomfort in the case of products subject to manual manipulation are usually assessed using questionnaires using rating scales to assess the characteristics 
examined (Boyles et al, 2003; Chandra and Chandna, 2011; Lee and Chen, 2008; Carse et al, 2007). Also are used pain maps, measurement of pain and discomfort assessment (Kihlberg et al, 1995; Trejo et al, 2006; Lin and McGorry, 2009). Subjective evaluations have some disadvantage: they require a large number of participants and therefore require a lot of time (Lee et al, 1993), and they are influenced by personal preferences (Chen et al, 1994). Some commonly known causes of unreliability in the use of subjective measures are time error and context effects (Annet, 2002). Therefore, it is advisable to use objective measurements in addition to subjective measurements (Bisht and Khan, 2013). Various techniques are available to obtain information on consumer preferences and most involve the use of questionnaires or interviews. The form of the questions asked is extremely important. Questions must be asked in such a way that the answers can be quantitatively analyzed. One way to achieve this is to ask questions in the form of a rating scale and ask the subject to define a rating from a scale that corresponds to his assessment. The answers can be followed by questions, which can be of an open type that reveal the reasons for a certain answer/grade. For example, if the answer to the previous question was very difficult or difficult, the following question could be: what were the reasons for the difficulty? Answers to such open-ended questions often provide information about possible improvements to the products being tested. Another way to obtain additional information of this type is to use checklists where all possible difficulties are listed from which the respondent chooses the ones he experienced during the test. It is useful to include at the end of the questionnaire general assessment questions that allow the respondent to define the acceptability of the product he/she observes as a whole. An example of study based on the subjective method is the study by Winder et al. (2002) that was designed to examine the relationship between consumers, their complaints about food and beverage packaging, and the occurrence of injuries and accidents when opening food and beverage packaging. Two hundred customers from four Sainsbury stores filled out a four-page questionnaire. Participants answered questions about eight different categories of packaging (canned goods, canned goods with a ring, cans, plastic bottles and jars, glass bottles and jars, cardboard boxes/packaging, flexible packaging and "tray goods"). Examples of these categories of packaging were presented to participants through photographs.

\subsection{Mechanical methods}

The mechanical method implements a mechanical test and it is quite fast and easily reproducible. Mechanical testing measures only one dimension (force) that is used for a particular job/action and requires certain equipment. The measurements aim to provide the lower limit of force required when consumers perform the required action using the product. However, as the measurements do not mimic the human use of the product, they can only be used as an indicator of the required level of force, and the measurement failure caused by this varies from package to package. The method does not involve human perception. The level of force depends on factors such as adhesion, the slipperiness of the material and the type of mechanism and these factors are not included in the mechanical test. To create a replication of the packaging opening procedure, various instruments such as meters are used. The Danish Technological Institute (Heinö et al, 2008) has been measuring the torque required to open the packaging. The equipment used was the Instron 5569 torque meter. Samples were prepared by emptying the entire contents and cutting out the mechanism for opening each sample of the packaging. Wires and clamps were used to mimic the force-displacement during the opening procedure for most measurements. It was necessary to open the packaging in two operations. The bottle tester, Tornado (JKM systems, DK), was used to measure torque during the opening of the lid of medical products. The packaging was attached to the measuring cell. The cover is released manually and the maximum required torque is measured (Figure 7a) in the first step. Then the second step of the experiment involves the pullring method of the lid with the ring for pulling the opening which can be seen in Figure $7 \mathrm{~b}$.
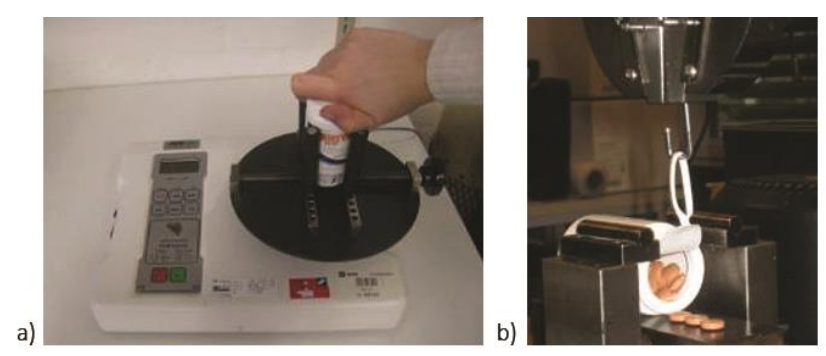

Figure 7: Experimental apparatus used in Danish research a) the first step b) the second step (Heinö et al., 2008) 
Tetra pak (Heinö et al, 2008) used the Instron torque meter to investigate the opening of the packaging and to measure the torque during the opening of the lid. The packaging for medical products is attached to a plate that registers torque, and the rotating fixture opens the lid. The Zwick machine is used to measure the force when opening the lid with the pull ring (Figure 8). The fixture holds the packaging at 20 degrees and the pull ring is fastened with a clamp attached to the movable clamp. The pulling head moves upwards at a speed of 100 $\mathrm{mm} / \mathrm{min}$, and the force is measured by a measuring cell. The measurement is completed when the diaphragm of the pull ring is completely loosened.

a)

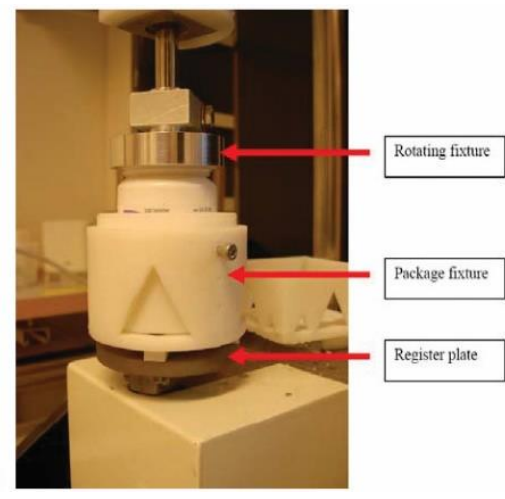

b)

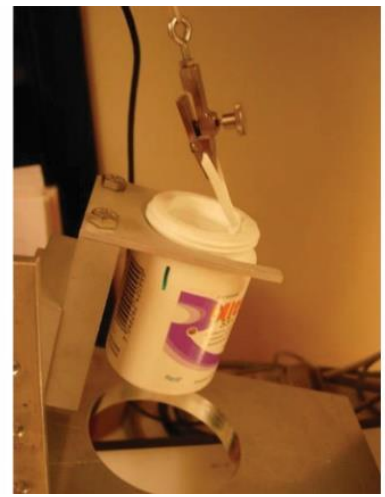

Figure 8: Experimental apparatus used in Tetra pak research a) the first step b) the second step (Heinö et al., 2008)

\subsection{Objective methods}

Objective methods are a combination of subjective and mechanical methods. Objective methods help to provide scientific logic and the reason behind subjective answers. In most cases, in addition to subjective estimates by users, some objective parameters are also recorded. Different user responses can be attributed to the levels of different physiological and biomechanical responses of the human body. The choice of parameters to be collected is based on the type of research being conducted and on the parts of the body involved in performing the task. Measuring the anthropometry of the hands is a key activity that is usually performed in various research papers dealing with any research in which the user uses the hands. Researchers have conducted various studies such as examining the optimal grip span concerning an individual's anthropometry for isometric power grip exertion (Eksioglu, 2004). Objective measurements such as pressure pain threshold measurements (Madeleine et al, 2003), joint and body posture and deviation, grip force/force/ torque, (Motamedzade et al, 2007; Jung, 2008; Wu et al, 2009) and the size and distribution of hand pressure (Aldien et al, 2005) are some of the frequently performed measurements in objective methods (Bisht and Khan, 2013). Various researches have been performed in the field of ease of opening packaging. Packaging that has torque-requiring closures (Heinö et al, 2008; Yoxall et al, 2006; Yoxall et al, 2008) that require a coordinated two-handed procedure are assessed as particularly challenging. A lot of the research work that can be found is based on the measurement of torque forces (Yoxall et al, 2006; Carus et al, 2006; Duizer et al, 2009; Langley et al, 2005; Yoxall et al, 2010; Yoxall and Rowson, 2015).

\subsection{Usability methods}

In addition to subjective and objective methods of product evaluation and tasks, usability methods are widely used to study user performance while using a product. Various metrics such as safety, reliability, ease of use (Woods and Buckle, 2005; Wu et al, 2008; Vanderwal et al, 2011), task efficiency, precision, stability, duration (Lee and Chen, 2008; Wu et al, 2009; Jung and Hallbeck, 2005; Chang et al, 2007), etc. researchers have used it in the past to assess the usability of different types of products. To measure the parameters of different metrics that are responsible for assessing the usability of a test, the parameters would have to be both subjective and objective in nature. Data can be collected using various rating scales and ranking procedures, direct observation or using equipment such as algometer, dynamometer, goniometer, heart rate monitor, accelerometer, etc. (Bisht and Khan, 2013). Opening vacuum-sealed jars can be a problem for a large percentage of the elderly population (Berns, 1981) because they are unable to exert sufficient turning force, and it is a topic that is continuously being researched. In research screw force required to open the jar is usually examined. With such packaging, a minimum torque is required to maintain the vacuum. No regulations are prescribing the torque required to open 
the jar. The degree of torque applied in the production process is often high because other factors are involved, such as preventing people from accidentally opening jars or stopping consumers from rummaging through the product before purchase (Voorbij and Steenbekkers, 2002). Several studies have been conducted to characterize the opening moments of typical glass jar packaging (Peebles and Norris, 2003; Voorbij and Steenbekkers, 2002; Carse et al, 2011) as well as to examine the torques typically required to remove the lid (Janson, 2007) and what impact the change in shape and dimensions of the lid has on opening moments (Crawford et al, 2002). By researching of Wei-Ting et al. (2016) examined several lid design features (diameter, height, tip shape, side view shape, and surface texture) using controlled laboratory testing with older women with hand function limitations. The subjective evaluation procedure was applied to examine the main effects and interactions of cover design characteristics on usability, determined by the perceptions of the effort and discomfort of the participants. In addition to the subjective assessment, an objective assessment of the lids was designed by creating a special experiment where objective results were collected. Each participant's diameter-specific maximum voluntary torque was tested at the beginning of the test session by turning a prototype model of the jar lid. Similarly, in the research of Carse, Thomson and Stansfield (2011), a new measuring device was used to characterize torque and pressure during a dynamic jar opening action by a younger and older adult. Older adults tend to twist the jar lid more slowly ( $0.038 \mathrm{Nm}$ / s vs $0.044 \mathrm{Nm} / \mathrm{s}$ ) and open the jar at a slower speed (0.84 Rad / s vs $1.59 \mathrm{Rad} / \mathrm{s})$ than younger people while using a higher proportion of their maximum grip strength (40\% vs. $27 \%$ ) indicating that older adults used a more cautious opening strategy. These differences suggest that a simple test of maximum torque is not enough to characterize the abilities of older adults concerning opening the packaging. Usability tests are more complexed since sometimes special equipment needs to be built, but the results that can be obtained can better represent a real human interaction with the packaging.

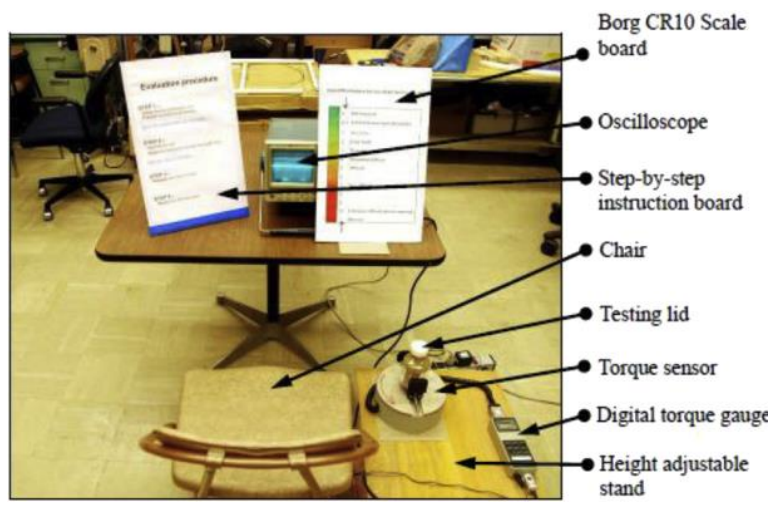

Figure 9: Experimental setup (Wei-Ting et al., 2016)

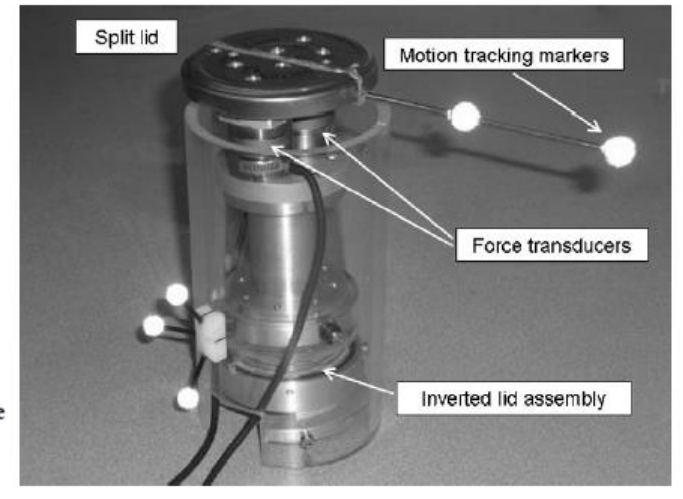

Figure 10: Experimental apparatus (Carse et al,, 2011)

\section{CONCLUSIONS}

Ergonomically designed packaging is becoming an increasingly popular demand among consumers. Ergonomically designed packaging implies that it is easy to open, allows easy access to a product that is packed in it, has a good closing system if the goods are not intended to be consumed at the first opening. Ergonomically design packaging should be adjusted to the size of the user's hand, it should not require excessive physical force from the user, etc. Easy opening of the packaging becomes the main problem that users face in their interaction with packaging. All consumers face this problem but people with disabilities, the elderly, people with some kind of hand problem mostly deal with this. The type of required grip and the possibility of applying the force required to open the packaging differ depending on the type of packaging. To proper develop an ergonomically shaped packaging, physical qualifications and consumer capabilities and possible critical aspects of packaging that can affect using the product should be considered. In this paper, a review of methodologies that can be implemented in the design development, analysis and evaluation of work tasks and packaging shape was given. Methods for assessing critical aspects of product use can be divided into subjective methods, mechanical methods, objective methods and usability methods.

When the product should be evaluated based on of the comfort it provides to the user, subjective methods and measurements are most often used. Most of them are focused on the discomfort that the user feels when using the product. Subjective methods are useful for assessing comfort, productivity, and ease of use of a product. Subjective comfort and discomfort in the case of products that undergoes 
manual manipulation are usually assessed using questionnaires or through conducting interviews. Subjective evaluations have some clear shortcomings: they require a large number of respondents and therefore research takes a long time, and they are influenced by personal preferences. There are some commonly known sources of the unreliability of the use of subjective measures, such as time error and context effects.

Mechanical tests measure the force required to use a product. The measurements aim to provide the lower limit of power required when consumers perform the required action using the product. However, as the measurements do not mimic the human use of the product, they can only be used as an indicator of the required level of strength, and this varies from packaging to packaging. The level of force depends on factors such as adhesion, the slipperiness of the material and the type of mechanism and these factors are not included in the mechanical test. The mechanical test is quite fast, easy and cheap to implement. Mechanical testing measures only one dimension (strength) used for a particular job and requires certain equipment.

Objective methods help to verify the authenticity of subjective tests based on our knowledge of the physical and biomechanical limitations and capacities of the human body. The objective method is a combination of subjective methods and mechanical methods. Objective methods also help to provide scientific logic and reason behind subjective answers.

In addition to subjective, mechanical, and objective methods of evaluating products and tasks, usability methods are widely used for studying consumer while using a product. To measure the various parameters responsible for assessing the usability of a test, the parameters would have to be both subjective and objective in nature. Data can be collected using various rating scales and ranking procedures, direct observation or using equipment such as algometer, dynamometer, goniometer, heart rate monitor, accelerometer, etc. Often a special equipment is built for a particular experiment which makes the method more complex but also can gives more interesting and more correct results.

Each of these methods can be useful for ergonomic research of packaging products. If the research goal and research hypotheses are clearly defined and if the research setting is defined in accordance with the rules proposed by the type of selected method, then the research results will be of high quality.

\section{ACKNOWLEDGMENTS}

This research (paper) has been supported by the Ministry of Education, Science and Technological Development through the project no. 451-03-68/2020-14/200156: "Innovative scientific and artistic research from the FTS (activity) domain".

\section{REFERENCES}

[1] Aldien, Y., Welcome, D., Rakheja, S., Dong, R., Boileau, P. E.: “Contact pressure distribution at hand-handle interface: role of hand forces and handle size", International Journal of Industrial Ergonomics 35, 267-286, 2005.

[2] Annet, J.: "Subjective rating scales: science of art?", Ergonomics 45(14), 966-987, 2002. doi: 10.1080/00140130210166951.

[3] Armstrong, T., Cochran, D. J., Bleed, P. A., Lin, J-H., Freivalds, A., Radwin, R. G., Rempel, D. M.: “Hand Tool Ergonomics - Past and Present", Proceedings of the Human Factors and Ergonomics Society Annual Meeting 2010, pp. 1145-1148. doi:10.1177/154193121005401512.

[4] Berns, T.: "The handling of consumer packaging", Applied Ergonomics 12, 153-161, 1981.

[5] Bisht, D. S., Khan M. R.: "Ergonomic Assessment Methods for the Evaluation of Hand-Held Industrial Products: A Review", Proceedings of the World Congress on Engineering 2013, (WCE: London, U.K., 2013.).

[6] Boyles, J. L., Y earout, R. D., RYS, M. J.: "Ergonomic scissors for hairdressing", International Journal of Industrial Ergonomics 32, 199-207, 2003.

[7] Bridger, R. S.: "Introduction to Ergonomics", (Taylor \& Francis, New York, 2003.).

[8] Carse, B., Thomson, A., Stansfield, B.: "A novel device for evaluating forces during the dynamic jar opening action: Do older and younger adults do things differently?", Medical Engineering and Physics 33, 521-525, 2011. doi: 10.1016/j.medengphy.2010.11.017.

[9] Carse, B.,Thomson, A., Stansfield, B.: "Packaging and the Older Adult", An International Conference on Inclusive Design 2007, (Helen Hamlyn Centre at the Royal College of Art, London, UK, 2007.). 
[10] Carus, D.A., Grant, C., Wattie, R., Pridham, M.S.: "Development and validation of a technique to measure and compare the opening characteristics of tamper-evident bottle closures", Packaging Technology and Science 19(2), 105-118, 2006. doi:10.1002/ pts.721.

[11] Chandra, A., Chandna, O.: "Ergonomic design of hand tool (screwdriver) for Indian worker using comfort predictors: a case study", International Journal of Advanced Engineering Technology 2(4), 231-238, 2011

[12] Chang, B. C., Huang, B. S., Chen, C. K., Wang, S. J.: "The pincer chopsticks: The investigation of a new utensil in pinching function",Applied Ergonomics 38, 385-390, 2007. doi: 10.1016/j.apergo.2006.03.009.

[13] Chebykin, O. Y., Bedny, G. Z., Karwowski, W.: "Ergonomics and Psychology Developments in Theory and Practice", (Taylor \& Francis Group, Boca Raton, 2008.).

[14] Chen, H., Nigg, B. M., Koning, J. D.: "Relationship between plantar pressure distribution under the foot and insole comfort", Clinical Biomechanics 9, 335-342, 1994. doi: 10.1016/02680033(94)90062-0.

[15] Consumer and Competition Policy Directorate: "Specific Anthropometric and Strength Data for People with Dexterity Disability", (DTI, Great Britain, 2002.).

[16] Crawford, J.O., Wanibe, E., Nayak, L.: "The interaction between lid diameter, height and shape on wrist torque exertion in younger and older adults", Ergonomics 45(13), 922-933, 2002. doi: 10.1080/00140130210162243.

[17] Duizer, L. M., Robertson, T., Han, J.: “Requirements for packaging from an ageing consumer's perspective", Packaging Technology and Science 22(4), 187-197, 2009. doi:10.1002/pts.834.

[18] Dul, J.: "Ergonomics for Beginners: A Quick Reference Guide [Kindle version]", 3rd Edition, (TNO Institute, 2008.).

[19] Eksioglu, M.: "Relative optimum grip span as a function of hand anthropometry", International Journal of Industrial Ergonomics 34, 1-12, 2004. doi: 10.1016/j.ergon.2004.01.007.

[20] Freivalds, A. : "Biomehanics of the upper limbs: Mechanics, modeling and musculoskeletal injuries", 2nd Edition, (CRC Press Taylor \& Francis Group, Boca Raton, 2011.).

[21] Hashim A., Dawal, S. Z.: "K ano Model and QFD integration approach for Ergonomic Design Improvement", Procedia - Social and Behavioral Sciences 2012, The 2012 International (Summer) Conference on Business Innovation and Technology Management, (Elsevier, Genting, Malaysia, 2012), pages 22-32. doi: 10.1016/j.sbspro.2012.09.1153.

[22] Heinö, R-L., Åström, A., Antvorskov, H., Mattsson, M., Østergaard S.: “Easy Open Pack Scientific background for the basis of an international standard for easy-to-open packages", ( Nordic cooperation project (NICe), Norway, 2008.).

[23] Janson, R. G.: "Openability of vacuum lug closures", PhD thesis, Department of Mechanical Engineering, University of Sheffield, 2007.

[24] Johnson, J.: Applying Ergonomics to Tool Design, In: Alexander, D. (eds.), “Applied Ergonomics: Case Studies, 1", (GA: Engineering and Management Press, Norcross, 1999.).

[25] Jung, H. S.: "Design of liquid container handles in accordance with user preferences", Ergonomics 51(3), 247-260, 2008. doi: 10.1080/00140130701636157.

[26] Jung, M. C., Hallbeck, M. S.: "Ergonomic redesign and evaluation of a clamping tool handle", Applied Ergonomics 36, 619-624, 2005. doi: 10.1016/j.apergo.2005.01.016.

[27] Kaljun, J., Dolšak, B.: "Ergonomic design knowledge built in the intelligent decision support system", International Journal of Industrial Ergonomics 42, 162-71, 2012. doi: 10.1016/j.ergon.2011.11.009.

[28] Kihlberg, S., Kjellberg, A., Lindbeck, L.: "Discomfort from pneumatic tool torque reaction: Acceptability limits", International Journal of Industrial Ergonomics 15, 417-426, 1995. doi: 10.1016/0169-8141(94)00059-C.

[29] Kroemer Elbert, K.E., Kroemer, H. B., Kroemer Hoffman, A. D.: “Ergonomics - How to Design for Ease and Efficiency", 3 rd Edition, (Academic Press, 2018.). doi: https://doi.org/10.1016/C2016-0$\underline{02516-0 .}$

[30] Kumar, S.: "Biomechanics in Ergonomics", (Tylor and Francis, UK, London, 1999.).

[31] Langley, J., Janson, R., Wearn, J., Yoxall, A.: "Inclusive' design for containers: improving openability", Packaging Technology and Science 18(6), 285-293, 2005. doi:10.1002/pts.699.

[32] Lee, K. S., Ferraiuolo, D., Temming, J.: "Measuring seat comfort", Automotive Engineering 101(7), 25-30, 1993.

[33] Lee, Y. C, Chen, Y. L.: "An auxiliary device for chopsticks operation to improve the food-serving performance”, Applied Ergonomics 39, 737-742, 2008. doi:10.1016/j.apergo.2007.11.006. 
[34] Lin, J. H., McGorry, R. W.: "Predicting subjective perceptions of powered tool torque reactions", Applied Ergonomics 40, 47-55, 2009. doi: 10.1016/j.apergo.2008.01.020.

[35] Madeleine, P., Lundager, B., Voigt, M., Arendt-Nielsen, L.: "Standardized low-load repetitive work: evidence of different motor control strategies between experienced workers and a reference group", Applied Ergonomics 34, 533-542, 2003.

[36] Moore, S. M., Torma-Krajewski, J., Steiner, L. J.: "Practical Demonstrations of Ergonomic Principles. Report of investigations/2011, RI 9684", (Department of Health and Human Services, Centers for Disease Control and Prevention, National Institute for Occupational Safety and Health, Pittsburgh, 2011.).

[37] Motamedzade, M., Choobineh, A., Mououdi, M. A., Arghami, S.: "Ergonomic design of carpet weaving hand tools", International Journal of Industrial Ergonomics 37, 581-587, 2007. doi: 10.1016/j.ergon.2007.03.005.

[38] Nordenskiöld, U.: "Daily Activities in Women with Rheomatoid and Arthritis", PhD thesis, University of Gothenburg, 1996 .

[39] Norris, B. J., Wilson, J. R.: “CHILDATA: The Handbook of Child Measurements and CapabilitiesData for Design Safety", (Department of Trade and Industry, London, 1995.).

[40] Novaković, D.: "Grafička ambalaža", Materijal sa predavanja, GRID, Fakultet tehničkih nauka, Novi SAD, 2013.

[41] Oyewole, S. A., Haight, J. M., Freivalds, A.: "The ergonomic design of classroom furniture/computer work station for first graders in the elementary school", International Journal of Industrial Ergonomics 40, 437-47, 2010. doi: 10.1016/j.ergon.2010.02.002.

[42] Peebles, L., Norris, B. J.: “ADULTDATA: The Handbook of Adult Anthropometric and Strenght Measurements-Data for Design Safety", (Department of Trade and Industry, London, 1998.).

[43] Peebles L., Norris B. J.: "Filling 'gaps' in strength data for design", Applied Ergonomics 34, 73-88, 2003. doi:10.1016/S0003-6870(02)00073-X.

[44] Rogulj, N., Srhoj, Lj., Čavala, M.: "Differences in Anthropologic Characteristics between Kinesiologically Active and Inactive Female Students", Collegium antropologicum 36(3), 945-950, 2012.

[45] Rosengren, J., Brodin, N.: "Validity and reliability of the Swedish version of the Patient Specific Functional Scale in patients treated surgically for carpometacarpal joint osteoarthritis", Journal of Hand Therapy 26, 53-61, 2013. doi: 10.1016/j.jht.2012.10.007.

[46] Rowson, J., Yoxall, A.: "Hold, grasp, clutch or grab: consumer grip choices during food container opening", Applied Ergonomics 42(5), 627-633, 2011. doi:10.1016/j.apergo.2010.12.001.

[47] Salvendy, G.: "Handbook of human factors and ergonomics", 4th Edition, (Wiley, New Jersey, 2012.).

[48] Smith, S. A., Norris, B. J., Peebles, L.: "OLDER ADULTDATA: The Handbook of Measurements and Capabilities of Older Adult- Data for design Safety", (Department of Trade and Industry, London, 2000.).

[49] Stanton, N. A., Young, M. S., Harvey, C.: "A Guide to Methodology in Ergonomics: Designing for Human Use", 2nd Edition, (CRC Press, Boca Raton, 2014.).

[50] Sudarov, N., Fratić, F.: "Dijagnostika treniranosti sportista”, (Pokrajinski zavod za sport, 2010.).

[51] Trejo, A. E., Done, K. N., DiMartino, A. A., Oleynikov, D., Hallbeck, M. S.: "Articulating vs. conventional laparoscopic grasping tools- surgeons' opinions", International Journal of Industrial Ergonomics 36, 25-35, 2006. doi: 10.1016/j.ergon.2005.06.008.

[52] Vanderwal, L., Rautiainen, R., Kuye, R., Peek-Asa, C., Cook, T., Ramirez, N., Culp, K., Donham, K.: "Evaluation of long- and shorthandled hand hoes for land preparation, developed in a participatory manner among women vegetable farmers in The Gambia", Applied Ergonomics 42, 749-756, 2011. doi: 10.1016/j.apergo.2010.12.002.

[53] Voorbij, A. I. M., Steenbekkers, L. P. A.: "The twisting force of aged consumers when opening a jar", Applied Ergonomics 33, 105-109, 2002. Avalable from: doi: 10.1016/S0003-6870(01)00028-X.

[54] Wei-Ting, Y., Sommerich, C.M., Lavender S.A., Flinn S.R., Sanders E.B.N.: "Evaluation of jar lid design characteristics by older women with hand use limitations", Applied Ergonomics 52, 177-184, 2016. doi: 10.1016/j.apergo.2015.07.011.

[55] Winder, B. Ridgway, K., Nelson, A., Baldwin, J.: "Food and drink packaging: who is complaining and who should be complaining", Applied Ergonomics 33, 433-438, 2002. doi: 10.1016/s00036870(02)00026-1. 
[56] Woods, V., Buckle, P.: "An investigation into the design and use of workplace cleaning equipment", International Journal of Industrial Ergonomics 35, 247-266, 2005. doi: 10.1016/j.ergon.2004.09.004.

[57] Wu, S. P., Ho, C. P., Chi, H. C.: "Ergonomic study of a vertical rope-pulling task from a scaffolding", Ergonomics 51(3) 345-354, 2008. doi:10.1080/00140130701627875.

[58] Wu, X., Thomson, G., Tang, B.: "An investigation into the impact of safety features on the ergonomics of surgical scalpels", Applied Ergonomics 40, 424-432, 2009. doi: 10.1016/j.apergo.2008.11.003.

[59] Yoxall, A., Janson, R., Bradbury, S. R., Langley, J., Wearn, J., Hayes, S.: "Openability: producing design limits for consumer packaging", Packaging Technology and Science 19(4), 219225, 2006. DOI:10.1002/pts.725.

[60] Yoxall, A., Janson, R.: "Fact or friction: a model for understanding the openability of wide mouth closures", Packaging Technologyand Science 21(3), 137-147, 2008. doi:10.1002/pts.785.

[61] Yoxall, A., Langley, J., Janson, R., Lewis, R., Wearn, J., Hayes, S. A., Bix, L.: "How wide do you want the jar?: The effect on diameter for ease of opening for widemouth closures", Packaging Technology and Science 23(1), 11-18, 2010. doi:10.1002/pts.874.

[62] Yoxall, A., Rowson, J.: "Talking about torque: measuring pack accessibility - a review", Packaging Technology and Science 28(1), 1-14, 2015. doi:10.1002/pts.2079.

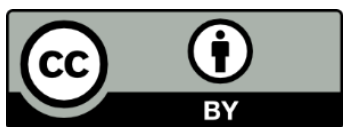

(C) 2020 Authors. Published by the University of Novi Sad, Faculty of Technical Sciences, Department of Graphic Engineering and Design. This article is an open access article distributed under the terms and conditions of the Creative Commons Attribution license 3.0 Serbia (http://creativecommons.org/licenses/by/3.0/rs/). 